\title{
66 3D LAVA FLOW MAPPING OF THE 17-25 MAY 2016 ETNA ERUPTION USING TRI-STEREO OPTICAL SATELLITE DATA,
}

\author{
Gaetana Ganci* $^{*}$, Annalisa Cappello ${ }^{1}$, Vito Zago ${ }^{1,2}$, Giuseppe Bilotta ${ }^{1}$, Alexis Hérault ${ }^{1,3}$, \\ Ciro Del Negro ${ }^{1}$ \\ (1) Istituto Nazionale di Geofisica e Vulcanologia, Sezione di Catania, Osservatorio Etneo, Catania, Italy \\ (2) Dipartimento di Ingegneria Elettrica Elettronica e Informatica, Università di Catania, Catania, Italy \\ (3) Conservatoire National des Arts et Métiers, Paris, France
}

Article history

Receveid August 8, 2018; accepted September 7, 2018.

Subject classification:

Etna volcano; Satellite remote sensing; Pléiades imagery; Digital elevation model.

\begin{abstract}
During basaltic eruptions, the average rate at which lava is erupted (effusion rate) is one of the most important factors controlling the evolution, growth and extent of the flow field. This has implications both for forecasting purposes, highlighting the importance of the effusion rate as input parameter of physics-based numerical models, and to advance knowledge on the shallow feeder system by constraining the supplied mass. Satellite remote sensing provides a mean to estimate the average effusion rate by applying a direct conversion from the measured radiant heat loss by an active lava flow. This conversion relies on a set of parameters of lava (e.g. rock density, heat capacity, vesicularity, emissivity, etc.) and suffers of multiple sources of uncertainties and measurements errors, whose quantification is still an open problem. Here we constrain the volume of lava emitted at Mt Etna on 17-25 May 2016 and emplaced out of the summit craters, by using pre-eruptive and post eruptive digital elevation models (DEMs) obtained processing satellite images acquired by the Pléiades constellation, which provides images at $50 \mathrm{~cm}$ resolution in stereo and tri-stereo mode. The 3D processing of the tri-stereo Pléiades imagery (acquired on 24 December 2015 and 18 July 2016), performed using the free and open source MicMac photogrammetric library, provides estimations of the distribution of thickness and the bulk volume emitted. The integration of multi-platform remote sensing products represents a new potential of merging capabilities to enable a more comprehensive response to effusive crises.
\end{abstract}

\section{INTRODUCTION}

Mount Etna is one of the most active and hazardous volcanoes in the world, well known for the persistent activity from the summit craters and frequent lava flow-forming eruptions from vents situated on the flanks of the volcano [Cappello et al., 2013; Acocella et al., 2016]. From 2011 to 2017, numerous eruptive episodes occurred; most of them characterized by the emission of lava fountains, pyroclastic material, and short-lasting lava flows that mostly spread within the Valle del Bove [Cappello et al., 2018; Ganci et al., 2018].
On the evening of May 17, 2016 an intense Strombolian activity started at the North-East Crater (NEC), followed by the emission of volcanic ash. This eruptive activity ended the following day, when the Voragine (VOR) began to erupt, producing a pulsating lava fountain and a small lava flow from the western rim of the Voragine-Bocca Nuova depression (Figure 1). On 18 May, a new eruptive vent opened at the eastern base of the NEC, near the two cones that formed during the July-August 2014 activity, which fed a lava flow that expanded towards the northern wall of Valle del Bove. This lava flow remained active until the early 


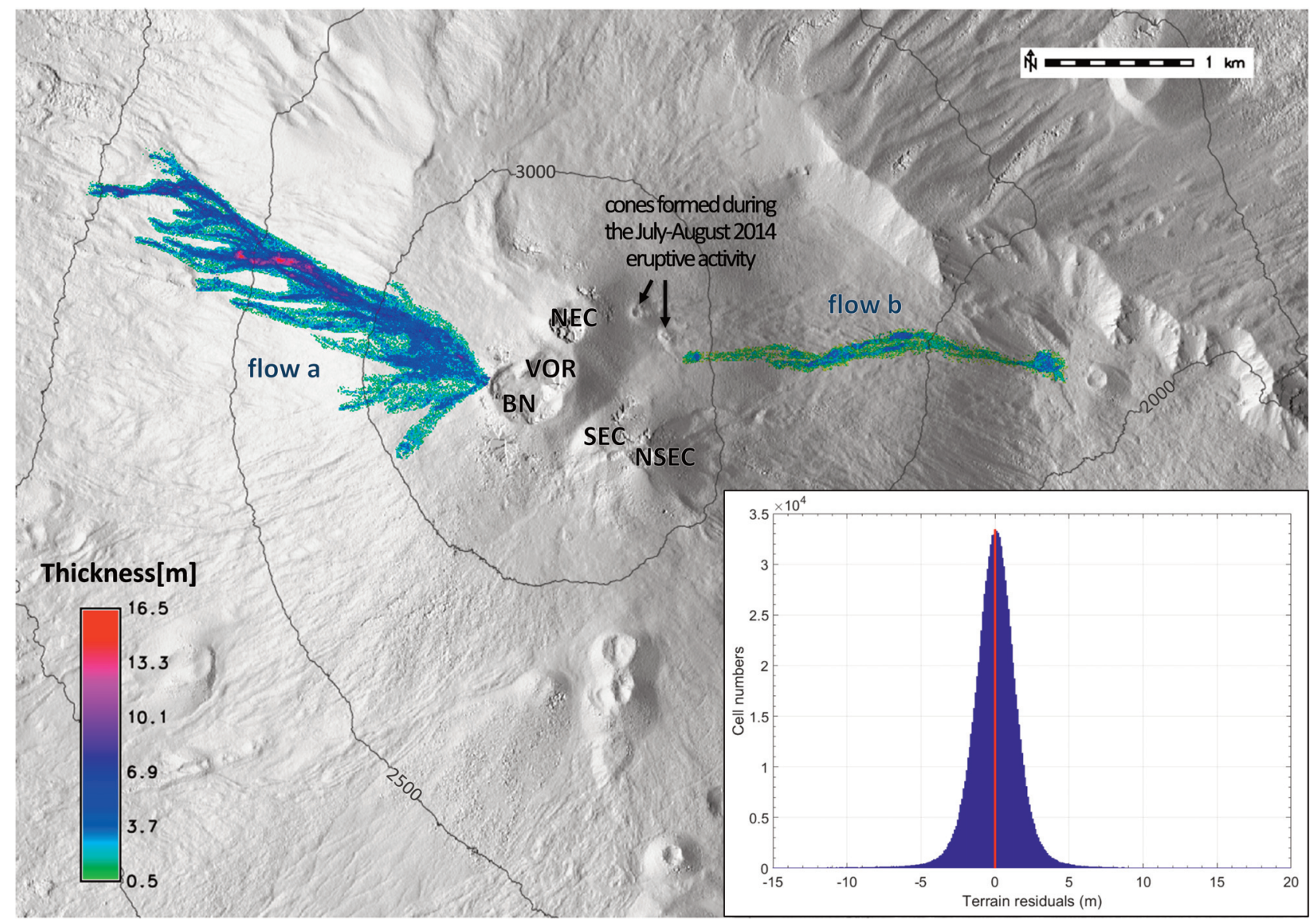

FIGURE 1. Elevation change obtained by differencing the two DEMs derived from Pleiades images acquired before (24 December 2015) and after (18 July 2016) the May 2016 Etna eruptions. Colors indicate the flow thickness in meters inside the lava flow fields. Flow a was emitted during the 18-19 and 22-25 May eruptive episodes occurred at BN and VOR. Flow b is the lava flow fed on 18-19 May by the eruptive vent opened at the eastern base of the NEC, near the July-August 2014 cones. The inset shows the zero-peaked histogram of the terrain residuals, proving the two DEMs are properly aligned. By Nuth and Kääb co-registration, the standard deviation of elevation changes was reduced from 5.3 to $1.6 \mathrm{~m}$.

morning of 19 May. During the morning of 19 May a new paroxysm occurred at the VOR, with the emission of a new lava overflow toward west, which descended over the lava of the previous evening. The sequence of summit eruptions at Etna in May 2016 ended with two episodes of intense Strombolian activity at the NEC during the night of 22-23 May, and at the VOR between 24 and 25 May, which fed multiple flows that covered the lavas emplaced during the 18-19 May events.

Mapping these volcanic deposits constitutes a critical component for constraining the average rate at which lava is erupted, controlling lava flow morphological parameters, and giving insights into emplacement processes [Del Negro et al., 2016]. However, the calculation of the amounts of lava erupted is still an open issue, and problems arise when trying to quantify the associated uncertainties [Ganci et al., 2018]. Photogrammetry, using both aerial- and satellite-im- agery, has been proven to be useful in monitoring volcanic activity and mapping volcanic hazards [Baldi et al., 2000; Gwinner et al., 2000; James et al., 2014; Neri et al., 2017; Smets et al., 2017; Carr et al., 2018]. The recent availability of high spatial resolution data acquired in stereo or tri-stereo configuration (e.g., Pléiades) gives new opportunities for frequently updating the topography and modeling the 3D shape of volcanic products by differencing successive topographies.

Here we employed Pléiades data, which provide images at $50 \mathrm{~cm}$ in stereo and tri-stereo mode, to derive digital elevation models (DEMs) and map the products emitted during the eruptive episodes occurred at Mt Etna between 17 and 25 May, 2016. We also computed some morphometric parameters (area, maximum length, thickness, and volume) from the three-dimensional distribution of the volcanic deposits obtained by DEM difference. 


\section{METHODS}

We produced two DEMs at a spatial resolution of 2 meters, starting from Pléiades primary images acquired on 24 December 2015 (pre-eruptive) and 18 June 2016 (post-eruptive) in tri-stereo mode containing RPC (Rational Polynomial Coefficient) files. Both images have been acquired with minimal cloud percentage (i.e. less than $5 \%$ ) and cover an area of about $15 \mathrm{~km} \times 15 \mathrm{~km}$, which includes the summit area of Etna volcano and almost all the Valle del Bove.

The processing of the tri-stereo Pléiades imagery was performed using the free and open source MicMac software (Multi-images Correspondances, Méthodes $\mathrm{Au}-$ tomatiques de Corrélation) [Rupnik et al., 2017] that performs: (i) tie points recognition and matching between images; (ii) calibration and orientation, recognizing relationships between viewpoints and objects; (iii) correlation, producing dense matching for 3D scene reconstruction. To retrieve areas, volumes and thickness distribution of the lava flows emplaced out of the summit craters on 17-25 May 2016, the difference between post eruptive and pre eruptive DEMs was computed.

A crucial step for deriving this difference is the coregistration between the two DEM datasets, since mis-

\section{RESULTS}

By subtracting the 2015 DEM from the 2016 one, we obtained the topographic changes due to the volcanic deposits emplaced during the eruptive activity of Etna occurred on May 2016 (Figure 1). In this way, we estimated the distribution of thickness, areas and volumes (Table 1) in correspondence of the flows emplaced during the 18-19 and 22-25 May eruptive episodes occurred at BN and VOR (flow a), and the flow emitted on 18-19 May by the eruptive vent opened at the eastern base of the NEC, near the JulyAugust 2014 cones (flow b).

We found that flow a exhibits an aerial extension of $1.14 \mathrm{~km}^{2}$ with a volume of $4.25 \times 10^{6} \mathrm{~m}^{3}$, while flow $\mathrm{b}$ has an area of $0.24 \mathrm{~km}^{2}$ with a volume of 0.4 $\times 10^{6} \mathrm{~m}^{3}$ (Table 1). Considering both lava flow fields, we found a cumulative area of $1.38 \mathrm{~km}^{2}$.

In order to quantify errors associated with volume estimation, we computed the histogram of the elevation differences outside the lava flow fields (inset of Figure 1) finding a standard deviation of $1.6 \mathrm{~m}$, which results in an error of $2.2 \times 10^{6} \mathrm{~m}^{3}$. The total volume is thus $4.65 \pm 2.2 \times 10^{6} \mathrm{~m}^{3}$.

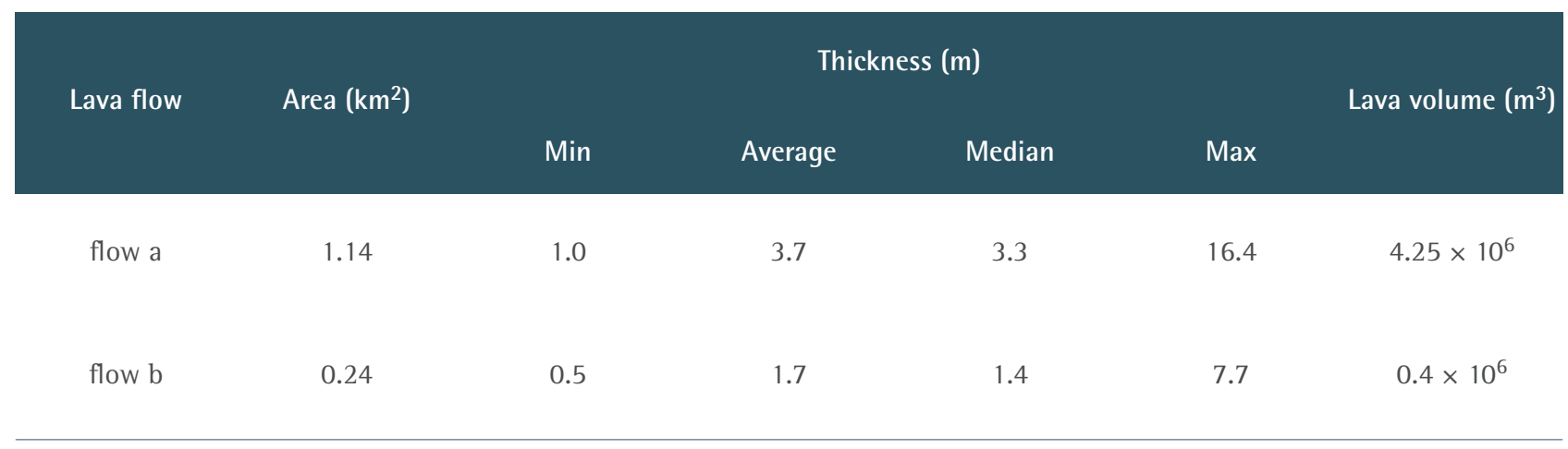

TABLE 1. Areas, thicknesses and volumes estimated for the two lava flows emplaced during the 18-19 and 22-25 May eruptive episodes occurred at BN and VOR (flow a), and the flow emitted on 18-19 May by the eruptive vent opened at the eastern base of the NEC (flow b).

aligned DEMs could result in a wrong estimation of elevation change.

We applied the co-registration method introduced by Nuth and Kääb [2011]. This methodology firstly finds iteratively the horizontal shift between two DEMs, based on a slope-aspect method, and removes it. Then, a potential elevation-depended error is checked and removed. Finally, higher-order biases are checked and corrected, by rotating the coordinate axis, if necessary (e.g. along/cross track corrections). Corresponding corrections, which result in a polynomial function, can be then applied.

\section{DISCUSSION AND CONCLUSIONS}

We quantified the topographic-derived volume and associated uncertainties of the lava flows erupted out of the summit craters of Mount Etna on May 2016.

Previously published results related to this eruption provided an estimation of $5.6-8.9 \times 10^{6} \mathrm{~m}^{3}$ for the cumulative volume infilling the BN-VOR depression and the western flow [Edwards et al., 2018]. Our estimation for the western flow (flow a in Figure 1) falls within this range, permitting to infer a volume of $3 \pm$ 


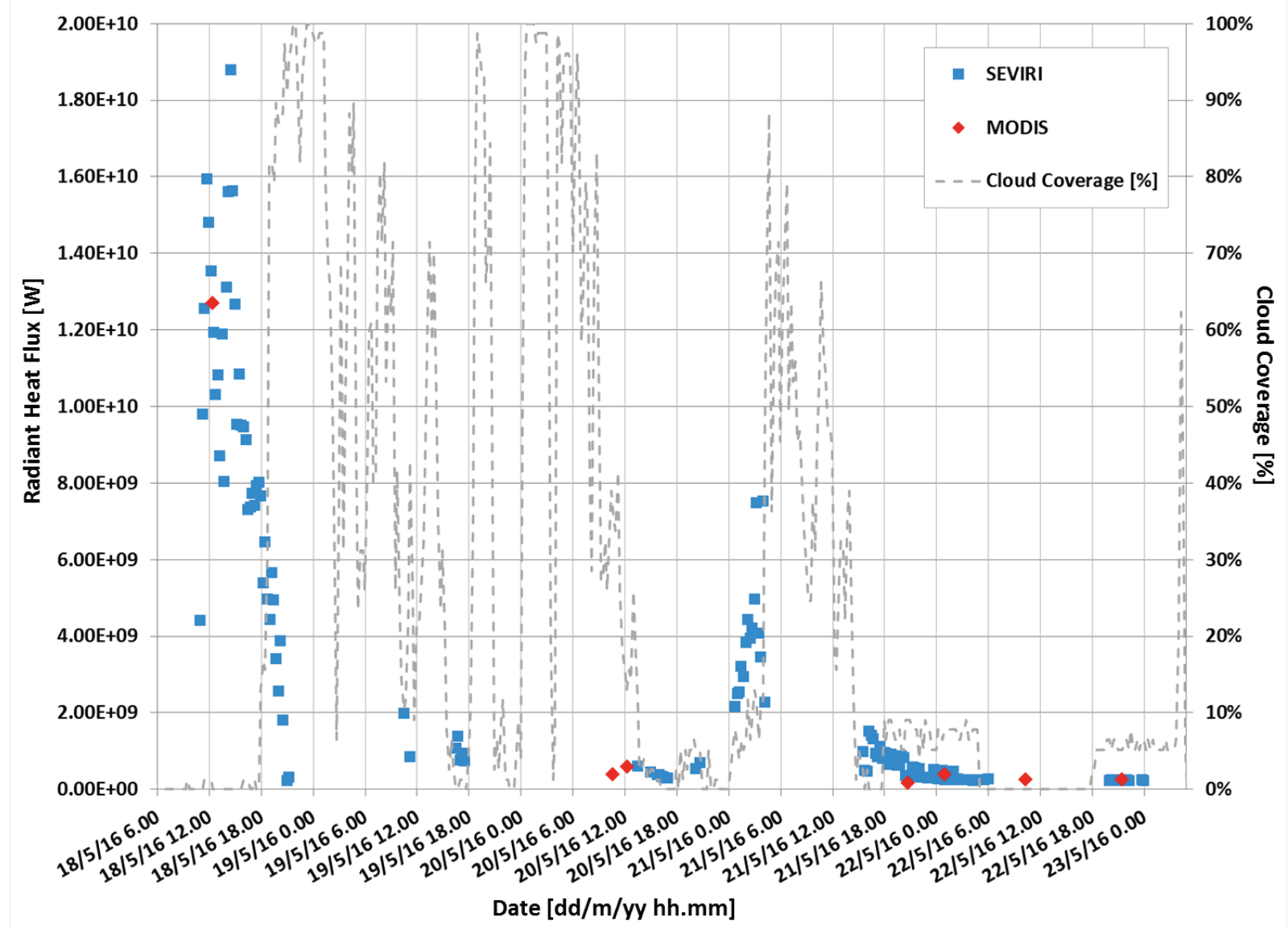

FIGURE 2. Radiant Heat Flux derived from SEVIRI (blue squares) and MODIS (red diamonds) data, and cloud coverage in percentage (dashed grey line) at Mt Etna during 18-23 May 2016.

$1.6 \times 10^{6} \mathrm{~m}^{3}$ for the BN-VOR depression.

Moreover, we found that the thickness distribution of flow b is in good agreement with typical field measurements related to the small lava flows emplaced on Valle del Bove [Behncke et al., 2014]. Indeed, by dividing flow $\mathrm{b}$ in five sectors based on the topography average slope, thickness ranges between: 0.9 and 2.3 $\mathrm{m}$ in the upper part of the flow (average slope: $7.4^{\circ}$ ), 0.5 and $1.5 \mathrm{~m}$ in the second sector (average slope: $11.3^{\circ}$ ), 0.9 and 2.9 in the third sector (average slope: $7.5^{\circ}$ ), 0.5 and $2.9 \mathrm{~m}$ in the fourth section (average slope: $13^{\circ}$ ), 1.1 and 3.1 in the last sector, which is the flattest area (average slope: $5.5^{\circ}$ ).

The total volume estimated from DEM differencing independently bounds the one derived from thermal satellite data processed via the HOTSAT system [Ganci et al., 2011b] (Figure 2). A cloud index has been computed considering the percentage of cloudy pixel in the volcanic area [Ganci et al., 2011a; 2016] since SEVIRI- and MODIS-derived radiant heat flux curves (respectively blue squares and red dots in Figure 2), are heavily affected by clouds (dashed grey curve). By ap- plying the cooling curve method introduced by Ganci et al. [2012], we inferred a total volume of $2.12 \times 10^{6}$ $\mathrm{m}^{3}$ expressed as dense-rock equivalent (DRE). Applying a correction of $25 \%$ for vesicularity to the topographic-derived bulk volume [Swainston, 2017], it yields $3.48 \times 10^{6} \mathrm{~m}^{3}$ of DRE volume. The volume difference of $1.36 \times 10^{6} \mathrm{~m}^{3}$ is mainly due to cloud coverage on IR satellite data.

The presented methodology provides new merging capabilities of multi-platform remote sensing products to monitor effusive eruptions, enabling a rapid response during effusive crises. In particular, the comparison with HOTSAT derived volumes provides a first order validation to the eruption rate derived from thermal satellite data, opening new perspectives in studying the conversion between radiant heat flux and time averaged effusion rate, which is still an open problem [Garel et al., 2012]. The 18-25 May eruption at Mt Etna was characterized by a small lava flow field, involving quite high relative errors associated with volume estimation. Nevertheless, since relative error decreases when increasing the thickness of the lava flow, this 
methodology would be particularly efficient for longlasting eruptions. Further research will include new study cases involving both Pléiades and infrared satellite data, in order to find new constraints to the radiant heat flux - eruption rate conversion, as eruptive conditions change.

Acknowledgements. Thanks are due to EUMETSAT for SEVIRI data. Pléiades data were available through the SVOP project. This work was developed within the framework of Tecnolab, the Laboratory for Technological Advance in Volcano Geophysics of the INGV in Catania (Italy) and was partially supported by the DPC-INGV 2012-2021 agreement. This paper benefited from the comments and suggestions of two anonymous reviewers.

\section{REFERENCES}

Acocella V., N. Neri, B. Behncke, A. Bonforte, C. Del Negro and G. Ganci (2016). Why does a mature volcano need new vents? The case of the New Southeast Crater at Etna. Front. Earth Sci. 4:67, doi:10.3389/feart.2016.00067.

Baldi, P., S. Bonvalot, P. Briole and M. Marsella (2000). Digital photogrammetry and kinematic GPS applied to the monitoring of Vulcano Island, Aeolian Arc, Italy. Geophysical Journal International, 142, 3, 801-811, doi: 10.1046/j.1365246x.2000.00194.x.

Behncke, B., S. Branca, R.A. Corsaro, E. De Beni, L. Miraglia and C. Proietti (2014). The 2011-2012 summit activity of Mount Etna: Birth, growth and products of the new SE crater. J. Volcanol. Geoth. Res., 270. doi: 10.1016/j.jvolgeores.2013.11.012.

Cappello, A., G. Bilotta, M. Neri and C. Del Negro (2013). Probabilistic modelling of future volcanic eruptions at Mount Etna, J. Geophys. Res. Solid Earth, 118. doi:10.1002/jgrb.50190.

Cappello, A., Ganci, G., Bilotta, G., Herault, A, Zago, V., Del Negro, C., (2018) Satellite-driven modeling approach for monitoring lava flow hazards 1 during the 2017 Etna eruption, Ann. Geophys, (this issue) doi: 10.4401/ag-7792.

Carr, B.B., A.B. Clarke, J.R. Arrowsmith, L. Vanderkluysen and B.E. Dhanu, (2018). The emplacement of the active lava flow at Sinabung Volcano, Sumatra, Indonesia, documented by structure- from-motion photogrammetry, J. Volcanol. and Geotherm. Res., doi:10.1016/j.jvolgeores.2018.02.004.

Del Negro, C, A. Cappello and G. Ganci (2016). Quantifying lava flow hazards in response to effusive eruption. Geol. Soc. Am. Bull. 128, 752-763. doi: 10.1130/B31364.1.

Matthew, J.E., L. Pioli, D. Andronico, S. Scollo, F. Ferrari and A. Cristaldi (2018). Shallow factors controlling the explosivity of basaltic magmas: The 17-25 May 2016 eruption of Etna Volcano, J. Volcanol. and Geotherm. Res. 357, 425-436, doi:10.1016/j.jvolgeores.2018.05.015.

Ganci G, Vicari A, Bonfiglio S, Gallo G, Del Negro C (2011a). A texton-based cloud detection algorithm for MSG-SEVIRI multispectral images. Geomatics, Natural Hazards \& Risk, vol. 2, doi: 10.1080/19475705.2011.578263.

Ganci, G., Vicari, A., Fortuna, L., Del Negro, C. (2011b). The HOTSAT volcano monitoring system based on a combined use of SEVIRI and MODIS multispectral data, Ann. Geophys, 54, 5, 2011; doi: 10.4401/ag-5338.

Ganci, G., A.J.L., Harris, C. Del Negro, Y. Guehenneux, A. Cappello, P. Labazuy, S. Calvari and M. Gouhier (2012). A year of lava fountaining at Etna: volumes from SEVIRI. Geophys. Res. Lett., 39, L06305. doi:10.1029/2012GL051026.

Ganci, G., G. Bilotta, A. Cappello, A. Hérault, and C. Del Negro (2016). HOTSAT: a multiplatform system for the satellite thermal monitoring of volcanic activity. In: Harris, A. J. L., T. De Groeve., F. Garel \& S. A. Carn, (eds) Detecting, Modelling and Responding to Effusive Eruptions. Geological Society, London, Special Publications, 426, doi: 10.1144/SP426.21.

Ganci, G., Cappello, A., Bilotta, G., Herault, A, Zago, V., Del Negro, C. (2018) Mapping Volcanic Deposits of the 2011-2015 Etna Eruptive Events Using Satellite Remote Sensing, vol. 6, 83, doi: 10.3389/feart.2018.00083.

Garel, F., E., Kaminski, S.Tait and A. Limare, (2012). An experimental study of the surface thermal signature of hot subaerial isoviscous gravity currents: implications for thermal monitoring of lava flows and domes. J. Geophys. Res. 117, B02205. doi: 10.1029/2011JB008698.

Gwinner, K., E. Hauber, R. Jaumann, and G. Neukum, (2000). High-resolution, digital photogrammetric 
mapping: a tool for Earth science. Eos, Transactions American Geophysical Union, 81 (44), 513520.

James, M.R. and S. Robson (2014). Sequential digital elevation models of active lava flows from ground-based stereo time-lapse imagery, ISPRS Journal of Photogrammetry and Remote Sensing, 97, 160-170, doi:10.1016/j.isprsjprs.2014.08.011.

Neri M., M. De Maio, S. Crepaldi, E. Suozzi, M. Lavy, F. Marchionatti, S. Calvari and F. Buongiorno (2017). Topographic Maps of Mount Etna's Summit Craters, updated to December 2015, Journal of Maps, doi:10.1080/17445647.2017.1352041

Nuth, C. and A. Kääb (2011). Co-registration and bias corrections of satellite elevation data sets for quantifying glacier thickness change, The Cryosphere, 5, 271-290, doi:10.5194/tc-5-2712011.

Rupnik, E., M. Daakir and M. Pierrot Deseilligny (2017). MicMac - a free, open-source solution for photogrammetry. Open geospatial data, softw. stand. 2: 14. doi:10.1186/s40965-017-0027-2.

Smets, B., N. d'Oreye, M. Kervyn, and F. Kervyn (2017). Gas piston activity of the Nyiragongo lava lake: First insights from a Stereographic Time-Lapse Camera system, Journal of African Earth Sciences, 134, 874-887, doi:10.1016/j.jafrearsci.2016.04.010.

Swainston, H. (2017). The simulation and risk analysis of Mt Etna's May 2016 eruption. Master Thesis, School of Earth and Environmental Science BSc (Hons) Geological Hazards, University of Portsmouth.

"CORRESPONDING AUTHOR: Gaetana GANCI, Istituto Nazionale di Geofisica e Vulcanologia, Sezione di Catania, Osservatorio Etneo Catania, Italy

email: gaetana.ganci@ingv.it (c) 2019 the Istituto Nazionale di Geofisica e Vulcanologia. 